\title{
Formation of Mesoporous Materials from Silica Dissolved in Various NaOH Concentrations: Effect of pH and Ionic Strength
}

\author{
Jayhyun Park, ${ }^{1}$ Yosep Han, ${ }^{2}$ and Hyunjung Kim ${ }^{3}$ \\ ${ }^{1}$ R\&D Team, Institute of Mine Reclamation Corporation, Coal Center, 30 Chungjin-dong, Jongno-gu, Seoul 110-727, Republic of Korea \\ ${ }^{2}$ Department of Natural Resources and Environmental Engineering, Hanyang University, number 17 Heangdang-dong, Seongdong-gu, \\ Seoul 133-791, Republic of Korea \\ ${ }^{3}$ Department of Mineral Resources and Energy Engineering, Chonbuk National University, 664-14 Duckjin-dong 1Ga, Duckjin-gu, \\ Jeonju, Jeonbuk 561-756, Republic of Korea
}

Correspondence should be addressed to Hyunjung Kim, kshjkim@jbnu.ac.kr

Received 25 March 2012; Accepted 24 May 2012

Academic Editor: Hongchen Chen Gu

Copyright (c) 2012 Jayhyun Park et al. This is an open access article distributed under the Creative Commons Attribution License, which permits unrestricted use, distribution, and reproduction in any medium, provided the original work is properly cited.

\begin{abstract}
We describe the effects of $\mathrm{NaOH} / \mathrm{SiO}_{2}$ ratio and $\mathrm{pH}$ on the formation of mesoporous materials, which was synthesized via an alkalimetal hydroxide fusion method, from amorphous silica dissolved in $\mathrm{NaOH}$. Physical properties (e.g., specific surface area, pore volume, and pore size) of mesoporous materials synthesized at different conditions (i.e., $\mathrm{pH}, \mathrm{NaOH} / \mathrm{SiO}_{2}$ ratio) were evaluated through X-ray diffraction, nitrogen adsorption-desorption, and transmission electron microscope analyses. The results showed that, at the $\mathrm{NaOH} / \mathrm{SiO}_{2}$ ratios of $0.5,1$, and 2, gels were successfully synthesized while no product was formed at the $\mathrm{NaOH} / \mathrm{SiO}{ }_{2}$ ratios greater than 2 . Additionally, mesoporous materials were found to be formed at both $\mathrm{pH} 10$ and 11 while they were unstable under more alkaline conditions. The adsorption/desorption isotherm results for the mesoporous materials synthesized at around $\mathrm{pH} 11$ and with $\mathrm{NaOH} / \mathrm{SiO}_{2}$ ratios of $0.5-0.8$ showed a hysteresis loop characteristic of the bottle-neck pore shape. Furthermore, mesoporous materials with good physical properties were synthesized from all gels at $\mathrm{pH} 10$ regardless of sodium concentration.
\end{abstract}

\section{Introduction}

The field of mesoporous inorganics, which have the favorable characteristics of high specific surface area, ordered pore structure, and large pore volume, has grown rapidly. This is due to their potential applications as catalyst supports and environmental absorbents (e.g., [1-4]). Moreover, mesoporous materials have attracted much interest as their tunable pore size can be controlled from 1.5 to $10 \mathrm{~nm}$ by cationic surfactants with different chain lengths or swelling agents such as mesitylene $[5,6]$.

Mesoporous silica has been synthesized from a variety of silicate sources, including tetraethoxysilane (TEOS), sodium silicate, fumed silica, colloidal silica, and fly ash (e.g., [711]). One would expect the formation of mesoporous silica may not be sensitive to the silicate source. Rather, the motivating factor in choosing a silicate source for mesophase synthesis has been the primary particle size as this affects silicate dissolution. Provided the particles were extremely small and dissolved in water, as in the hydrolyzed state, the silicate source will be irrelevant.

Amorphous silica is capable of forming sufficient silanolates for the subsequent micelle formation at $\mathrm{NaOH} / \mathrm{SiO}_{2}$ molar ratios greater than 0.5 , even with the low energy input of stirring at room temperature. Thus, one can feasibly add no more $\mathrm{NaOH}$ than half the molar amount of silica during the synthesis of mesopores. Until now, only amorphous silica with a small enough primary particle size such that all of it is dissolved in a $\mathrm{NaOH} / \mathrm{SiO}_{2}$ molar ratio of less than 0.5 was used. These sources included fumed silica, fused silica, and colloidal silica.

Chang et al. [12] attempted to synthesize mesoporous materials by dissolving silicate in fly ash with $\mathrm{NaOH}$ concentrations greater than 0.5 . However, the result showed that the synthesized mesoporous and amorphous material mixture was imperfect. Although fly ash contains impurities such as $\mathrm{Fe}, \mathrm{Ca}, \mathrm{K}$, and $\mathrm{S}$, these did not dissolve to any significant amount and thus the imperfect mesoporous 
material could not be attributed to the impurities. Chang et al. [12] concluded that sodium ions may disturb the synthesis of mesoporous material. The effects of $\mathrm{Na}^{+}$or $\mathrm{Cl}^{-}$ions on the synthesis mechanism is not clear; however, several previous reports indicate that these guest ions do play an important role in the organic-inorganic templating mechanism [12-15]. In fact, Ryoo and Jun [14] reported that salt addition improved hydrothermal stability of MCM-41. They also reported that the self assembly mechanism was based on charge density matching and it was described by the so-called $\left[\mathrm{S}^{+}, \mathrm{I}^{-}\right]$pathway $[14]$-adding guest ions changed the charge density between the anionic silica surface and the cationic surfactant surface, and the change resulted in the synthesis of better mesoporous materials.

Research on the effects of ions on the pore structure of mesoporous materials synthesized will broaden the choices of silicate source materials in the application of the alkalimetal hydroxide fusion method from various minerals. Thus, the central parameters in the synthesis of mesoporous materials reported here were $\mathrm{pH}$ and ion strength in solution [13]. We considered these to be the key parameters for the preparation of better mesoporous materials. The effects of the amounts of hydrochloric acid $(\mathrm{HCl})$ added during synthesis and the concentrations of $\mathrm{Na}^{+}$and $\mathrm{Cl}^{-}$ions on the synthesis of mesoporous silica were investigated through $\mathrm{X}$ ray diffraction (XRD), nitrogen adsorption-desorption, and transmission electron microscope (TEM) analyses.

\section{Materials and Methods}

Amorphous silica microspheres (purity 99\%, Dongyang Chem. Co.) with a median particle size of $2.5 \mu \mathrm{m}$ were used as the silicate source for the synthesis of mesoporous materials. Sixty grams of silica was first dissolved in $0.5-3 \mathrm{M} \mathrm{NaOH}$ solution $(1000 \mathrm{~mL})$ by vigorous stirring at room temperature for $48 \mathrm{~h}$. The synthesis procedure of the mesoporous material was as follows: $13.8 \mathrm{~g}$ distilled water was added to $4.6 \mathrm{~g}$ hexadecyltrimethylammonium bromide (surfactant, CTAB, Fluka) and it was stirred until the solution became clean. The silica-containing solution was then combined with the surfactant solution, and the mixture was stirred for $30 \mathrm{~min}$. Mixing the two solutions generated white gels which later became mesoporous materials. The mixture was sealed in polypropylene bottles for hydrothermal treatment at $110^{\circ} \mathrm{C}$ in an autoclave. Following a $24 \mathrm{~h}$-aging period in the autoclave, the solution was then cooled to room temperature. The solution's $\mathrm{pH}$ was adjusted by the addition of $2 \mathrm{M} \mathrm{HCl}$ and it was again treated hydrothermally for $96 \mathrm{~h}$ at $110^{\circ} \mathrm{C}$. The $\mathrm{pH}$ of the synthetic gel was maintained in the range of 11.0 to 11.3 .

The final molar composition of the gel was $1 \mathrm{SiO}_{2}$ : $0.125 \mathrm{CTAB}: 0.5-3 \mathrm{NaOH}: 100 \mathrm{H}_{2} \mathrm{O}$ for those experiments investigating mesophase synthesis at high $\mathrm{pH}$. The experimental method for examining the $\mathrm{pH}$ effect was the same as above except that the $\mathrm{H}_{2} \mathrm{O} / \mathrm{SiO}_{2}$ molar ratio was 400 instead of 100 . The molar composition of the gel for those experiments that assessed the effects of dissolving the silicate in $\mathrm{NaOH}$ prior to mesophase synthesis was $1 \mathrm{SiO}_{2}: 0.125 \mathrm{CTAB}: x \mathrm{NaOH}: 200 \mathrm{H}_{2} \mathrm{O}$. The $\mathrm{NaOH} / \mathrm{SiO}_{2}$ ratio, which is designated $x$, ranged from 0.5 to 2 . The $\mathrm{pH}$ of the synthetic gel solutions was maintained between 10.2 and 11.0 with $2 \mathrm{M} \mathrm{HCl}$ to optimize the mesophase formation at $\mathrm{NaOH} / \mathrm{SiO}_{2}$ ratios of $0.5,1$, and 2 . The $\mathrm{pH}$ was measured using a pH meter (scan1000, EUtech, Singapore) with an AgAgCl electrode.

All the gels were filtered and washed several times using distilled water and they were then oven-dried at $60^{\circ} \mathrm{C}$. After drying for $24 \mathrm{~h}$, the gels were calcined at $540^{\circ} \mathrm{C}$ for $4 \mathrm{~h}$ to remove the organic surfactant. The XRD of calcined products was performed by using a powder X-ray diffractometer (DMAX III, Rigaku, Japan) that operates at $40 \mathrm{kV}$ and $40 \mathrm{~mA}$, with the $\mathrm{K} \alpha 1$ emission of copper at $\lambda=1.54 \AA$ in steps of 0.02 degree and a step rate of 1 degree $\mathrm{min}^{-1}$ over the range $2 \theta$ between 1.5 and 7 degrees. The specific surface areas were measured by using the $\mathrm{N}_{2}$-gas adsorption method with a Nova1000 (Quantachrome, USA). The pore size distribution was calculated by using BJH method. TEM analysis was performed for representative samples $(\mathrm{NaOH} / \mathrm{Si}=0.5$ and $\mathrm{pH} 11.1$ versus $\mathrm{NaOH} / \mathrm{Si}=0.5$ and $\mathrm{pH} 11.3$ ) with a Hitachi H9000-NAR electron microscope operating at $200 \mathrm{kV}$.

\section{Results and Discussion}

3.1. Mesoporous Silica Synthesized at High $p H(p H>11)$. Dissolution of silicate at the $\mathrm{NaOH} / \mathrm{SiO}_{2}$ ratio of $0.5 \mathrm{did}$ not yield a clear solution. This suggests that presumably the solid silicate was not fully dissolved. However, all of the silicate solutions with $\mathrm{NaOH} / \mathrm{SiO}_{2}$ ratios greater than 0.5 , were clear. A white gel was formed on the addition of CTAB to the solutions with $\mathrm{NaOH} / \mathrm{SiO}_{2}$ ratios of 0.5 , 0.8 , and 1 . For $\mathrm{NaOH} / \mathrm{SiO}_{2}$ ratios of 2 or 3 , the solutions became clear with stirring. After heating at $110^{\circ} \mathrm{C}$ for $24 \mathrm{~h}$ in an autoclave, the white gel disappeared in solutions with equimolar $\mathrm{NaOH} / \mathrm{SiO}_{2}$ ratios but it remained in solutions with $\mathrm{NaOH} / \mathrm{SiO}_{2}$ ratios of 0.5 and 0.8 .

Figure 1 shows the nitrogen adsorption-desorption isotherm characteristics of the samples that were synthesized at a $\mathrm{pH}$ greater than 11.1. The samples were synthesized at a $\mathrm{H}_{2} \mathrm{O} / \mathrm{SiO}_{2}$ molar ratio of 100 , and the $\mathrm{pH}$ was maintained in the range of 11.1 to 11.3 by the addition of either $\mathrm{HCl}$ or more water (final $\mathrm{H}_{2} \mathrm{O} / \mathrm{SiO}_{2}$ molar ratio = 400) after heating at $110^{\circ} \mathrm{C}$ for $24 \mathrm{~h}$. Although the samples' initial $\mathrm{NaOH} / \mathrm{SiO}_{2}$ ratio was 0.5 , the final $\mathrm{NaOH} / \mathrm{SiO}_{2}$ molar ratios were found to be $0.5,0.49$, and 0.45 after the adjustment to a $\mathrm{pH}$ of $11.3,11.2$, and 11.1 , respectively ( $\mathrm{HCl}$ additions of $0,0.01$, and 0.05$)$. We conclude that the sample at $\mathrm{pH} 11.1$ (final $\mathrm{NaOH} / \mathrm{SiO}_{2}=0.45$ ) was a typical MCM-41 as a sharp adsorption curve by capillary condensation of $\mathrm{N}_{2}$ gas was observed in the $P / P_{0}$ range of 0.15 to 0.3 (solid triangle in Figure 1). The size and shape of the adsorption/desorption isotherms (Figure 1) and TEM images (Figures 2(a) and $2(\mathrm{~b})$ ) indicate that lowering the $\mathrm{pH}$ favors mesoporous silica synthesis. The results for samples that were produced by the addition of more water rather than $\mathrm{HCl}$ for controlling the $\mathrm{pH}$ are not so easy to interpret. More noteworthy observation was that the synthesis at $\mathrm{pH} 11.1$ for both $\mathrm{H}_{2} \mathrm{O} / \mathrm{SiO}_{2}=100$ and $\mathrm{HCl} / \mathrm{SiO}_{2}=0.05$ yielded a mesoporous sample (solid triangle in Figure 1) while the synthesis for $\mathrm{H}_{2} \mathrm{O} / \mathrm{SiO}_{2}=400$ 


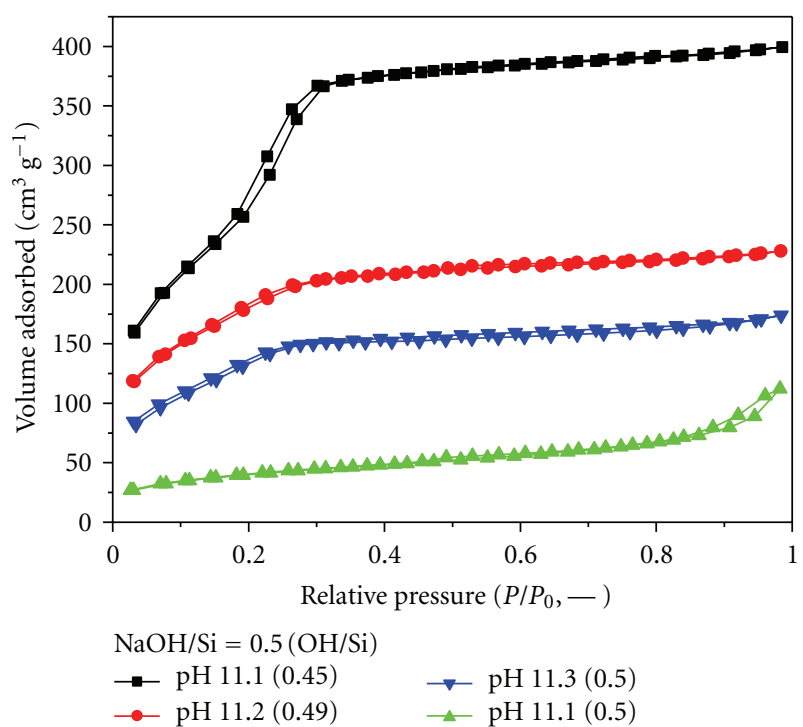

Figure 1: Nitrogen adsorption-desorption isotherms for mesophase products synthesized under various $\mathrm{pH}$ values. The $\mathrm{NaOH} /$ $\mathrm{SiO}_{2}$ was kept as 0.5 .

without $\mathrm{HCl}$ gave a nonporous silica (solid circle in Figure 1). The results indicate that a mesophase cannot be generated by simply varying the $\mathrm{pH}$, suggesting that the electrostatic interaction between cationic surfactant and anionic silicate likely depends on other factors other than $\mathrm{pH}$. Pastore et al. [16] reported that anions such as $\mathrm{Cl}^{-}$and $\mathrm{Br}^{-}$act as counter ions to the polar head groups of surfactants. They reported that the formation of rod-shaped micelles was likely due to the reduction of hydrophilic polar head area of the surfactant. Therefore, the formation of a hexagonal mesophase from $\mathrm{CTA}^{+}$micelles is expected to require some amount of $\mathrm{Cl}^{-}$for tuning the surfactant's polar head charge density. Recall the samples that were synthesized at $\mathrm{pH}$ 11.1 with the same $\mathrm{NaOH}$ concentrations: nonporous silica resulted from $\mathrm{H}_{2} \mathrm{O} / \mathrm{SiO}_{2}=400$ (solid circle in Figure 1), and a mesophase from $\mathrm{H}_{2} \mathrm{O} / \mathrm{SiO}_{2}=100$ (solid triangle in Figure 1). With the decreasing water content, it is expected that the concentration of guest ions such as $\mathrm{Na}^{+}, \mathrm{Br}^{-}$, and $\mathrm{Cl}^{-}$increased and the charge density was altered. Thus, it can be concluded that the water content influences mesophase synthesis.

Figure 3 shows the nitrogen adsorption-desorption isotherms of samples produced in various initial $\mathrm{NaOH}$ concentrations but at constant $\mathrm{pH}$ 11.1. Both the yield of solid samples and the amount of the adsorbed nitrogen gas were found to decrease with an increase in the $\mathrm{NaOH} / \mathrm{SiO}_{2}$ ratio. At the highest $\mathrm{NaOH} / \mathrm{SiO}_{2}$ ratios (2 and 3), the samples had low-pore volumes and their yields were less than 7\% and $5 \%$, respectively, based on the dissolved silica weight. Micropores exceeded mesopores for $\mathrm{NaOH} / \mathrm{SiO}_{2}$ ratios of 0.8 and 1. Moreover, a typical MCM-41 was obtained for the $\mathrm{NaOH} / \mathrm{SiO}_{2}$ ratio of 0.5 . Taken together, these suggest that high $\mathrm{NaOH}$ concentration before the acid treatment is undesirable in the mesoporous material synthesis. This can be attributed to the disturbed condensation of silanolate ions in the presence of a great amount of $\mathrm{NaOH}$. Even though the $\mathrm{pH}$ of the samples was identical, as the $\mathrm{NaOH} / \mathrm{SiO}_{2}$ ratio increased, the amounts of $\mathrm{NaCl}$ and excess $\mathrm{OH}^{-}$ ions in solution increased. The amount of $\mathrm{HCl}$ added for the $\mathrm{pH}$ adjustment was proportional to the $\mathrm{NaOH} / \mathrm{SiO}_{2}$ ratio before the acid treatment. The silanolates cannot be polymerized by the surplus $\mathrm{OH}^{-}$ions. The increase of $\mathrm{NaCl}$ molar concentration over that of silicate induced an increase in solution viscosity by neutralizing the charge of silicate oligomers and micelles. This increase in solution viscosity apparently reduced the diffusion of molecules and prevented silicate oligomer collision, which consequently did not allow for polymerization. In fact, solutions with $\mathrm{NaOH} / \mathrm{SiO}_{2}$ ratios of 2 and 3 were so viscous and nothing was produced in solution. A white gel was formed immediately in all the sample solutions as soon as the silicate solution contacted the cationic CTAB solution during synthesis. However, for the $\mathrm{NaOH} / \mathrm{SiO}_{2}$ ratio of 1 the gel disappeared at high temperature $\left(110^{\circ} \mathrm{C}\right)$. Furthermore, mesoporous silica was not formed in the case of high water content $\left(\mathrm{H}_{2} \mathrm{O} / \mathrm{Si}=\right.$ 400 ) without $\mathrm{Cl}^{-}$ions (solid circle in Figure 1) or the case of $\mathrm{NaOH} / \mathrm{SiO}_{2}$ ratios greater than 1 (Figure 3). These results suggest that all the initially and instantaneously aggregated gel mixtures may be unstable and that silicate condensation rate, which can be controlled by $\mathrm{NaOH}$ concentration, likely played a key role in the mesoporous material synthesis.

The products synthesized from various $\mathrm{NaOH} / \mathrm{SiO}_{2}$ ratios are compared in Figure 4. These materials were synthesized at a slightly higher $\mathrm{pH}$ (11.2) and lower water content $\left(\mathrm{H}_{2} \mathrm{O} / \mathrm{SiO}_{2}=70\right)$ than those in Figure 3. The nitrogen adsorption-desorption isotherms of the products that were synthesized with $\mathrm{NaOH} / \mathrm{SiO}_{2}$ ratios of 0.5 and 0.8 showed a step in the desorption branch for the pressure range of $\left(P / P_{0}\right) \quad 0.4$ to 0.5 (Figure $4(\mathrm{a})$ ), suggesting a hysteresis loop which was possibly formed from pores of the socalled bottle neck shape [17]. Figure 4(b) shows the pore size distribution obtained from the desorption curves of samples in Figure 4(a). The result for the $\mathrm{NaOH} / \mathrm{Si}$ ratio of 0.5 gave the broadest distribution of pore sizes with the modal pore size of $4 \mathrm{~nm}$ (perhaps the mouth of a bottle). This value is to some extent larger than the narrow pore diameter (2.7$2.9 \mathrm{~nm}$ ) for typical MCM-41 (the product synthesized with $\mathrm{NaOH} / \mathrm{SiO}_{2}=0.5$ in Figure 3). Nevertheless, the specific surface area was determined to be ca. $900 \mathrm{~m}^{2} \mathrm{~g}^{-1}$, which is quite similar to that of MCM-41 (solid triangle in Figure 3). For the samples synthesized with $\mathrm{NaOH} / \mathrm{SiO}_{2}$ ratios of 0.8 and 1.0, the specific surface areas were determined to be about 590 and $380 \mathrm{~m}^{2} \mathrm{~g}^{-1}$, respectively. These values were found to be quite low in comparison to those of MCM41 (900 to $\left.1400 \mathrm{~m}^{2} \mathrm{~g}^{-1}\right)$. Previous studies also reported similar hysteresis to that in Figure 4(a) in which the samples were synthesized at high temperatures $\left(160^{\circ} \mathrm{C}\right)$ or with the addition of salt $[18,19]$. The collapse of the pore structures during calcination in those cases was attributed to a large pore formation in the samples. However, much remains unknown regarding the mechanism of the formation of such a pore structure. For example, had the hexagonal rod-like pores been generated by the collapse of the pore walls, they would have shown wide rather than narrow pore distributions. The modal pore size in Figure 4(b) which was 


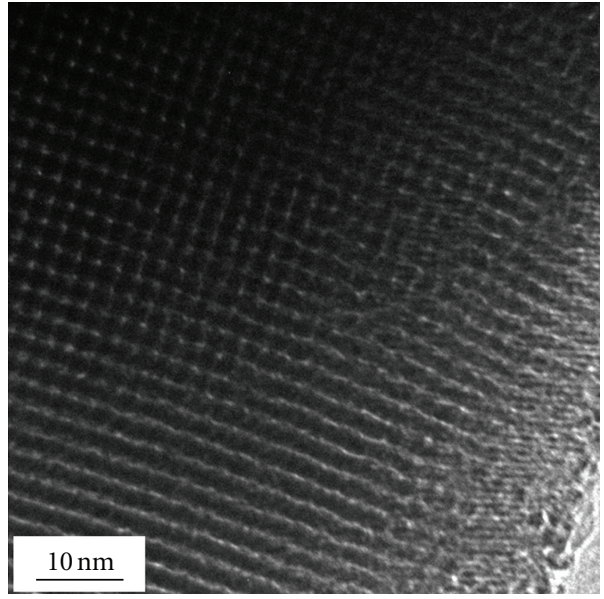

(a)

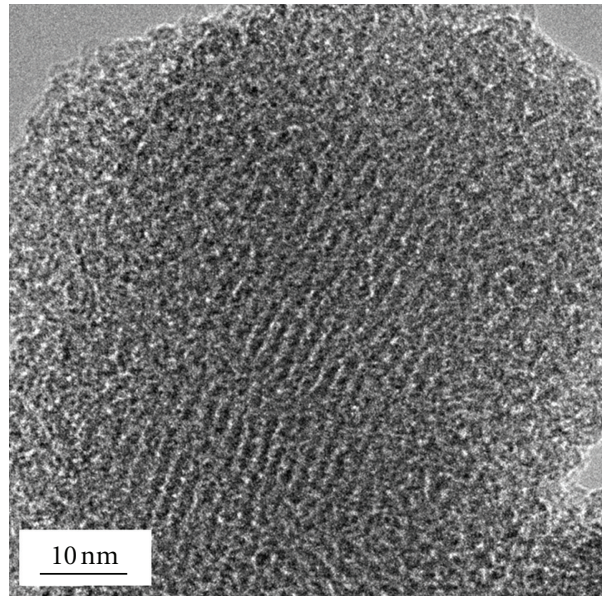

(b)

FIgURE 2: TEM images of mesoporous materials synthesized with $\mathrm{NaOH} / \mathrm{SiO}_{2}$ ratio of 0.5 at $\mathrm{pH} 11.1$ (a) and 11.3 (b). Corresponding nitrogen adsorption/desorption isotherms are presented in Figure 1 (solid triangle for $\mathrm{pH} 11.1$ and solid square for $\mathrm{pH} 11.3$ ).

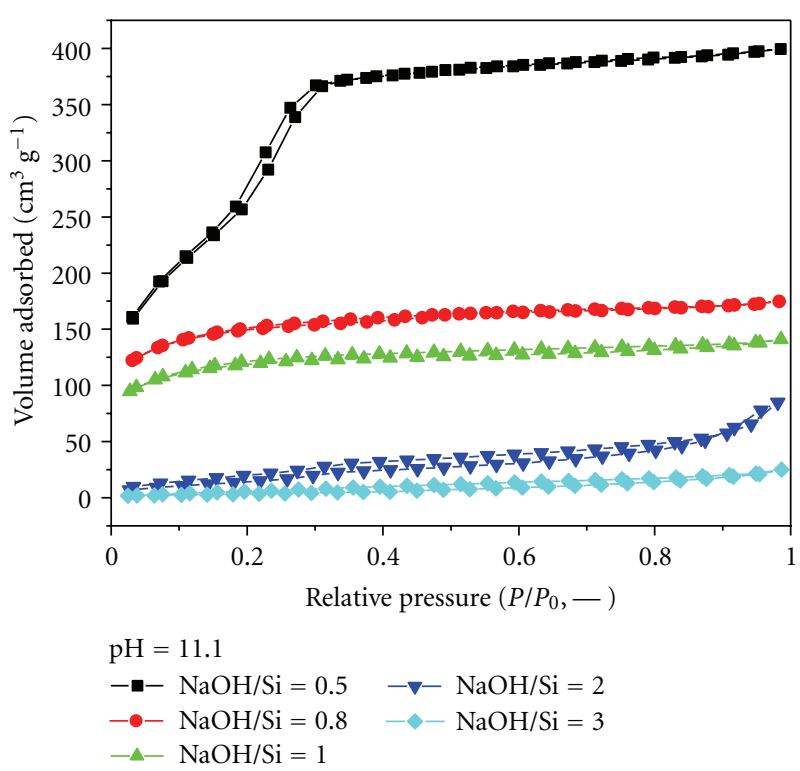

FIGURE 3: Nitrogen adsorption-desorption isotherms for mesophase products synthesized under various $\mathrm{NaOH} / \mathrm{SiO}_{2}$ ratios. The synthesis $\mathrm{pH}$ was kept as 11.1.

calculated from the desorption curve data, was determined to be consistently $4 \mathrm{~nm}$, indicating some form of systematic structural change. Mokaya [20] reported from TEM observation of silicate condensation over long times that the pore structure of MCM-41 was reconstructed from an initial rodlike pore shape to a fiber during the hydrothermal synthesis. Nitrogen adsorption-desorption isotherm of a sample, which exhibited a fibrous-like structure, also showed a De Boer type $\mathrm{V}$ hysteresis loop (bottle neck shape pore) after restructuring from the synthesized type I structure (tube shape pore) $[15,20]$. The restructure of a mesopore was related to the silicate growth, and the silicate growth was favored at $\mathrm{pH}$ greater than 11 and low salt concentrations. These together facilitated the dissolution of small silicate oligomers as well as their condensation onto a large silicate or concave solid surface. High temperatures caused silicate depolymerization. The accompanying change in the concentration of silanolate ions in solution will necessarily cause a change in the charge density on the silica surface, and this can prevent the condensation of the mesopore silica walls. This also explains the reason for the disappearance of the white gel from some samples after heating. The addition of sodium ions neutralized the silicate surface and removed the driving force for further aggregation of small oligomers. An increase in the quantity of small oligomers was seen as the growth rate of silicate rapidly decreased. According to the Thompson-Gibbs effect, small silicate oligomers are expected to be easily depolymerized. This is yet another factor that increased the amount of dissolved silicate in the solution. In summary, high temperature $\left(150^{\circ} \mathrm{C}\right)$ and salt (sodium ion) shift the polymerization/depolymerization equilibrium of silicate oligomers away from condensation. It is speculated that the reconstruction of the mesophase during hydrothermal synthesis is related to the degree of silica condensation. The pore structure of the samples in Figure 4(b) was reconstructed by the addition of the specific quantities of sodium ions. The condensation of silicate will be indispensable for the generation of silica walls between the mesopores. As higher synthesis temperatures and salt concentrations prevent the silicate condensation and instead catalyze silicate reconstruction, the conditions are expected to effectively prevent the mesophase formation.

3.2. Effect of $p H$. It is generally known that the hexagonal MCM-41 materials are synthesized at a $\mathrm{pH}$ greater than 11 and $\mathrm{NaOH} / \mathrm{Si}$ ratio less than 0.5 [9]. Lindlar et al. [21] suggested that at a $\mathrm{pH}$ less than 11, amorphous silica precipitated during the $\mathrm{pH}$ adjustment procedure, further dissolution of silicate did not occur, and the best synthesis 


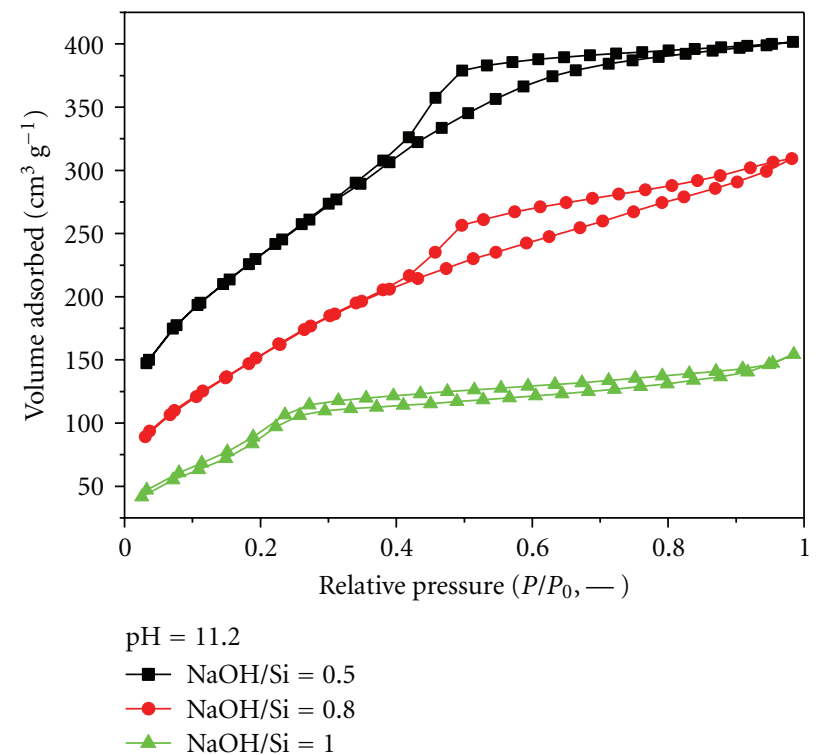

(a)

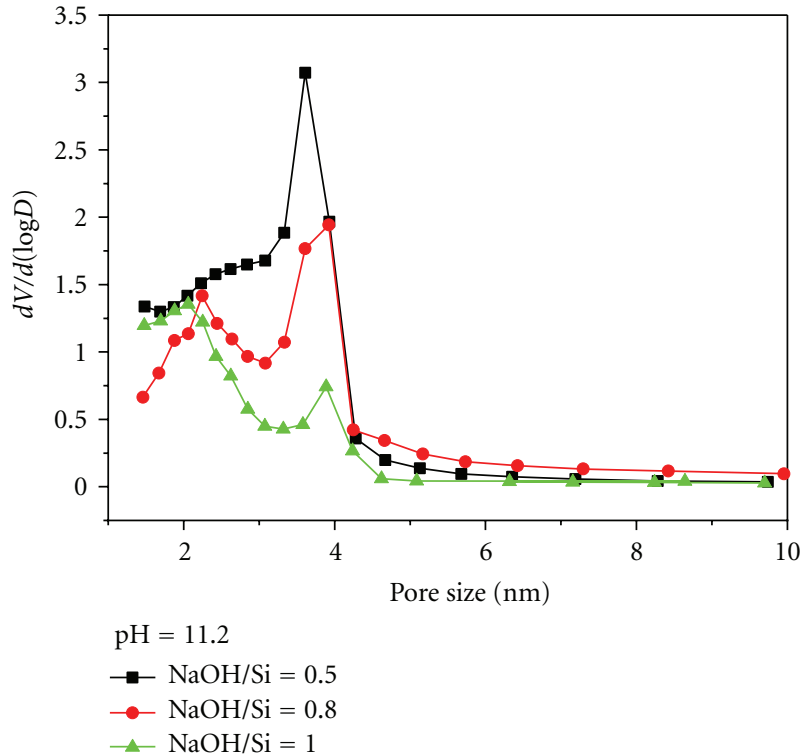

(b)

Figure 4: Nitrogen adsorption-desorption isotherms (a) and pore size distributions (b) for hexagonal mesophase products synthesized under various $\mathrm{NaOH} / \mathrm{SiO}_{2}$ ratios. The synthesis $\mathrm{pH}$ and $\mathrm{H}_{2} \mathrm{O} / \mathrm{SiO}_{2}$ were kept as 11.2 and 70 , respectively.

TABLE 1: Summary of the synthesis conditions for the samples in Figure $5^{\mathrm{a}}$.

\begin{tabular}{lcc}
\hline Initial $\mathrm{NaOH} / \mathrm{SiO}_{2}$ & $\mathrm{HCl} / \mathrm{SiO}_{2}$ after $24 \mathrm{~h}$ & $\mathrm{pH}$ after $\mathrm{HCl}$ addition \\
\hline 1 & 0.16 & 11.3 \\
1 & 0.32 & 11 \\
1 & 0.48 & 10.7 \\
1 & 0.64 & 10.4 \\
1 & 0.8 & 10 \\
\hline
\end{tabular}

${ }^{\mathrm{a}} \mathrm{SiO}_{2} / \mathrm{H}_{2} \mathrm{O}=1 / 400$.

of MCM-41 was prevented. This suggests that the synthesis of MCM-41 with minimal amorphous silica should be done at high $\mathrm{pH}$. In fact, most previous studies reported that mesoporous materials were produced at a $\mathrm{pH}$ greater than 11.

The XRD patterns of calcined materials obtained by the adjustment of the $\mathrm{pH}$ from 11.3 to 10.0 in the $\mathrm{NaOH} / \mathrm{Si}=$ 1 solution, showed that lower $\mathrm{pH}$ values provided a better hexagonal mesophase of MCM-41 type (the increase in the peak intensity of $d_{100}$ spacing in Figure 5 ). The best product was obtained at $\mathrm{pH} 10$. Table 1 showed the synthesis $\mathrm{pH}$ and the amount of $\mathrm{HCl}$ added to the sample solutions for the synthesis of the samples in Figure 5. Similar results for the synthesis of mesoporous structures at relatively low $\mathrm{pH}(10-10.2)$ have been reported $[6,22]$. These studies suggested that lowering the $\mathrm{pH}$ by acid adjustment can lead to the protonation of negatively charged silicates that surround the micelle. The electrostatic repulsion between silicate species would then be reduced. Thus, the coagulation of silicate species on the micelle template mixture and the condensation of $\mathrm{Si}-\mathrm{O}-\mathrm{Si}$ bonds are expected to be facilitated and a mesoporous material be formed. The silica wall thickness around the micelle at $\mathrm{pH} 10.7$ was determined to be about $17 \AA$. The thickness was roughly $19 \AA$ at both $\mathrm{pH}$ 10.4 and 10.0. The similarity in wall thickness indicated that most silanolates were condensed at $\mathrm{pH} 10.4$ (Figure 5(a)).

The $\mathrm{pH}$ of mesophase synthesis varied according to the kind of counter ion used [18]. In the presence of a chloride ion (acidification using $\mathrm{HCl}$ ), the lamellar phase was produced within the range of 11.1 to 11.6 , with a silicate dissolution at $\mathrm{pH}$ greater than $11.6[18,23]$. According to the previous studies $[18,24]$, the hexagonal phase was synthesized from the lamellar phase without the appearance of the intermediate cubic phase by lowering the $\mathrm{pH}$ from 11.6 to 10.4 at $\mathrm{NaOH} / \mathrm{SiO}_{2}$ ratios less than 0.5. Nevertheless, the XRD pattern characteristic of the lamellar phase was not observed for the samples at $\mathrm{pH} 11.3$ and 11.0 in Figures 5(a) and 5(b). We speculate that the high water content and the presence of guest ions, especially the relatively large amount of $\mathrm{Na}^{+}$versus $\mathrm{Cl}^{-}$, caused a change in the charge densities of micelle and silicate oligomers, suggesting that the results did not satisfy the criteria for lamellar phase formation. The XRD peak of the product at $\mathrm{pH} 11.3$ is broad through the $2 \theta$ range of 2 to $5^{\circ}$ although its intensity is very small (A in Figure 5(b)). The peak for $\mathrm{pH} 11.0$ is also broad (B in Figure 5(b)), but narrower than that for $\mathrm{pH} 11.3$ (A in Figure 5(b)). The specific surface areas of these two products were determined to be around $600 \mathrm{~m}^{2} \mathrm{~g}^{-1}$, so it is unlikely that they are simply nonporous amorphous silica. There has been a recent report for a mesopore synthesis mechanism whereby post acid treatment caused a disordered phase that had been generated in the initial synthesis stage to be converted to the hexagonal phase over a period of several days $[18,25]$. One concedes that the formation of the 


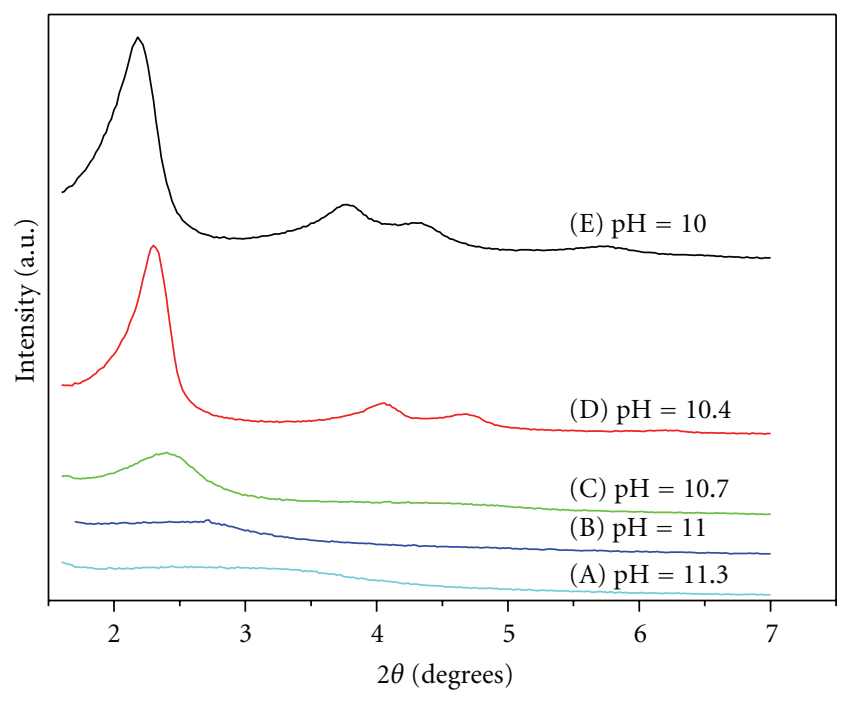

(a)

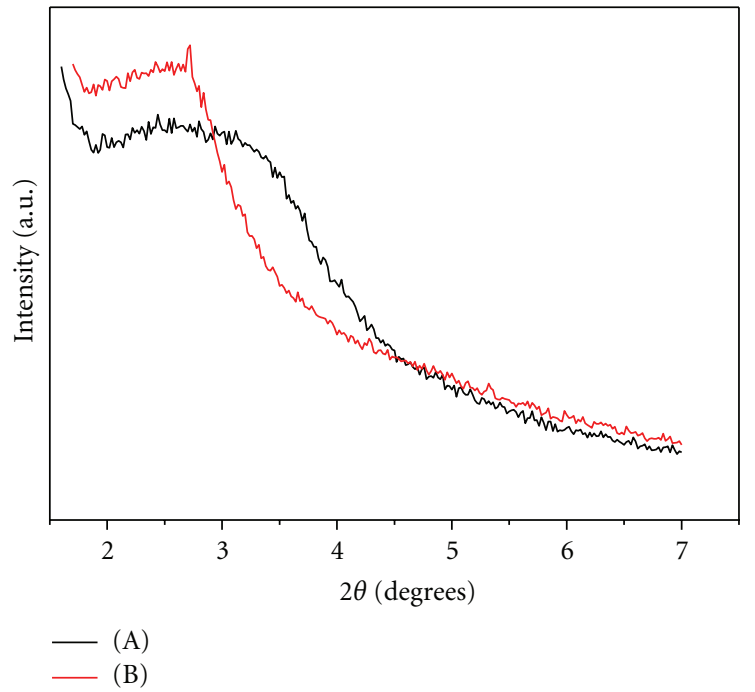

(b)

FIGURE 5: Small angle XRD powder patterns for the products synthesized at (A) $\mathrm{pH}=11.3,(\mathrm{~B}) \mathrm{pH}=11.0,(\mathrm{C}) \mathrm{pH}=10.7,(\mathrm{D}) \mathrm{pH}=10.4$, and $(\mathrm{E}) \mathrm{pH}=10.0$ (a). $\mathrm{NaOH} / \mathrm{Si}$ was kept as 1. Enlarged patterns for the samples A and B are presented in (b).

MCM-41 structure may have another mechanistic pathway for self ordering from any intermediate phase (whether disordered, rod-like, or other mixed phase) to the hexagonal phase, in addition to the generally-known pathway of phase transition from lamellar to hexagonal that accompanies a decrease in the $\mathrm{pH}$.

Figure 5(a) shows that as the synthesis $\mathrm{pH}$ decreased from 10.7 to 10.0 , the main peak ( $\mathrm{d}_{100}$ spacing) shifted slightly to the left. This indicated an increase in the pore size. Figures 6(a) and 6(b) also show that the pore size and the pore volume of products increased as the $\mathrm{pH}$ decreased. It is readily understandable that low $\mathrm{pH}$ favors the formation of well-ordered mesoporous silicate as the amount of silicate binding to micelles increases with decreasing $\mathrm{pH}$. However, the explanation for the increase in the pore size with decreasing $\mathrm{pH}$ remains unknown. The increase in the pore sizes is often attributed to the shrinkage of the silicate walls via silicate condensation as the hydrothermal time increases. However, the condensation-shrinkage of silicate seems hard to explain the phenomena as the pore size increased only slightly with decreasing $\mathrm{pH}$. Furthermore, the hydrothermal times were equal for the samples at $\mathrm{pH} 10.4$ and 10.0. Moreover, the products had the same wall thickness. It has been suggested that the pore size increased with decreasing $\mathrm{pH}$ as the addition of $\mathrm{HCl}$ increased the concentration of $\mathrm{Cl}^{-}$, which reduced the electrical repulsion of the cationic surfactants. Furthermore, the reduced electrical repulsion increased the aggregation number of the surfactants, which favored the formation of larger micelles [26].

3.3. Effect of $\mathrm{NaOH} / \mathrm{SiO}_{2}$ Molar Ratio. In order to synthesize mesoporous materials using natural minerals such as fly ash, clay, or low grade solid silicate species as opposed to alternative high grade sources such as fumed silica, dissolving the silicate in an aqueous solution of $\mathrm{NaOH}$ is required and thus the molar ratio of $\mathrm{NaOH}$ to $\mathrm{SiO}_{2}$ must be at least 0.5. A high concentration of $\mathrm{NaOH}$ is expected to favor the dissolution of solid state silica; however, the more $\mathrm{NaOH}$ a silicate solution contains, the more acid is required to maintain a constant $\mathrm{pH}$ during synthesis. There is a further complication; the post acid adjustment leads to an increase in the concentrations of dissolved silicate species and guest ions.

Figure 7 shows the pore size distributions of mesoporous samples with various $\mathrm{NaOH} / \mathrm{SiO}_{2}$ ratios subject to various acid adjustments. The corresponding pore characteristics are also presented in Table 2. For the samples with $\mathrm{NaOH} / \mathrm{SiO}_{2}$ ratio of 0.5 , the best mesoporous products were obtained at $\mathrm{pH} 10.5$ (solid diamond in Figure 7(a)). The modal pore size of the mesoporous products for $\mathrm{pH} 10.8,10.7$, and 10.4 was determined to be $2.5 \mathrm{~nm}, 2.5 \mathrm{~nm}$, and $2.9 \mathrm{~nm}$, respectively. However, contrary to this trend the product for $\mathrm{pH} 10.2$ had a smaller modal pore size $(2.5 \mathrm{~nm})$, pore volume, and specific surface area (Figure 7(a) and Table 2). For samples with $\mathrm{NaOH} / \mathrm{SiO}_{2}$ of 1 and 2, synthetic silicas obtained at $\mathrm{pH}$ greater than 11 were only slightly microporous or non-mesoporous (Figures 7(b) and 7(c)). The best ordered hexagonal mesophase at the $\mathrm{NaOH} / \mathrm{SiO}_{2}$ ratios was obtained in the $\mathrm{pH}$ range of 10.5 to 10.6. The poorest hexagonal mesoporous materials were formed with the decrease in the $\mathrm{pH}$ in the range of 10.5 to 10.2. A similar trend for decreasing $\mathrm{pH}$ was seen for the samples with $\mathrm{NaOH} / \mathrm{SiO}_{2}$ of 0.5 . When the $\mathrm{pH}$ was controlled between 10.5 and 10.6, the hexagonal mesoporous material was obtained regardless of the initial synthesis concentration of $\mathrm{NaOH}$. In those conditions, the presence of $\mathrm{Na}^{+}$ions seemed to have no significant effect 

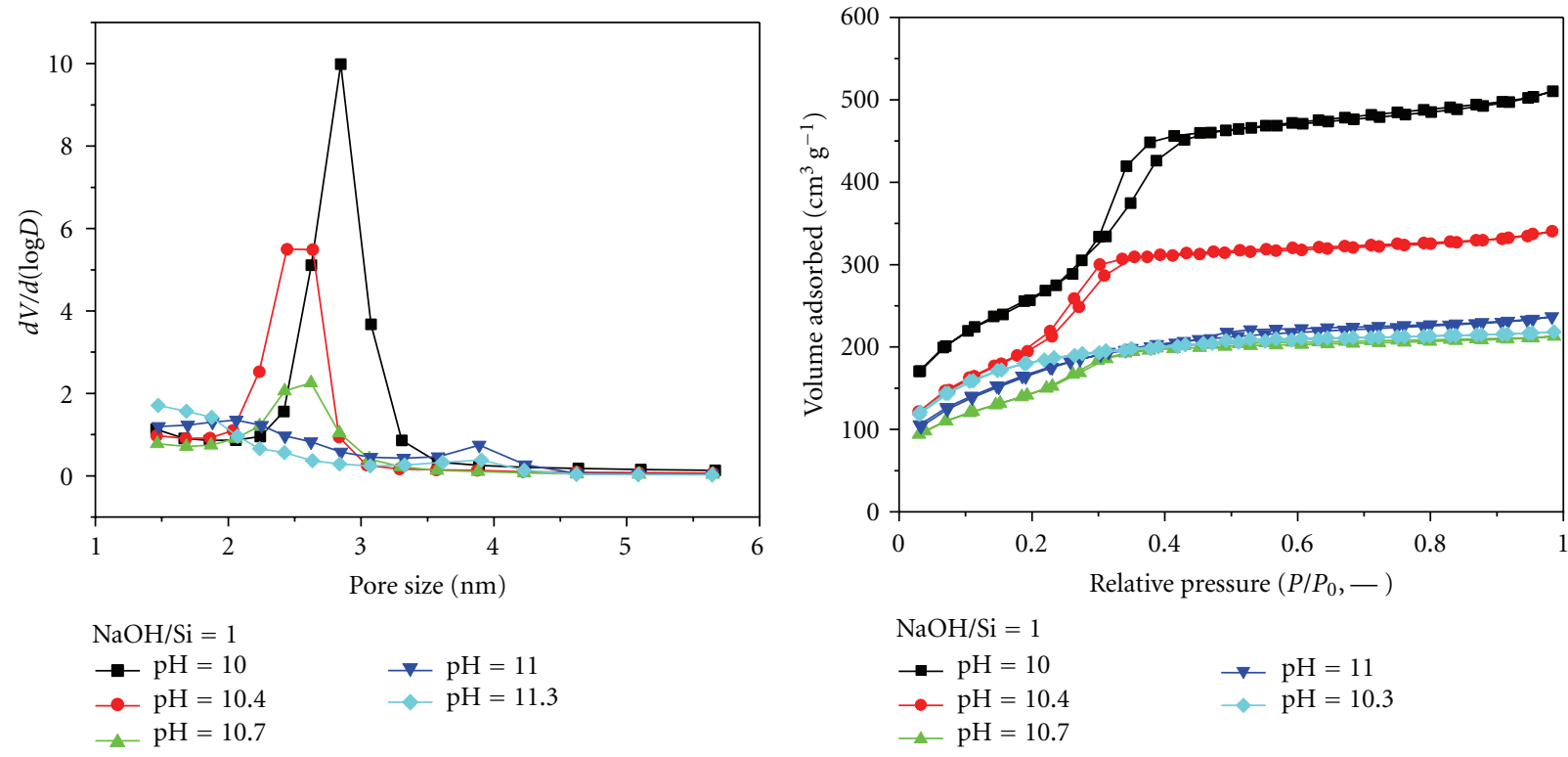

(a)

(b)

Figure 6: Pore size distributions (a) and Nitrogen adsorption-desorption isotherms (b) for the mesophase products synthesized under various $\mathrm{pH}$ values. The $\mathrm{NaOH} / \mathrm{SiO}_{2}$ was kept as 1.0.

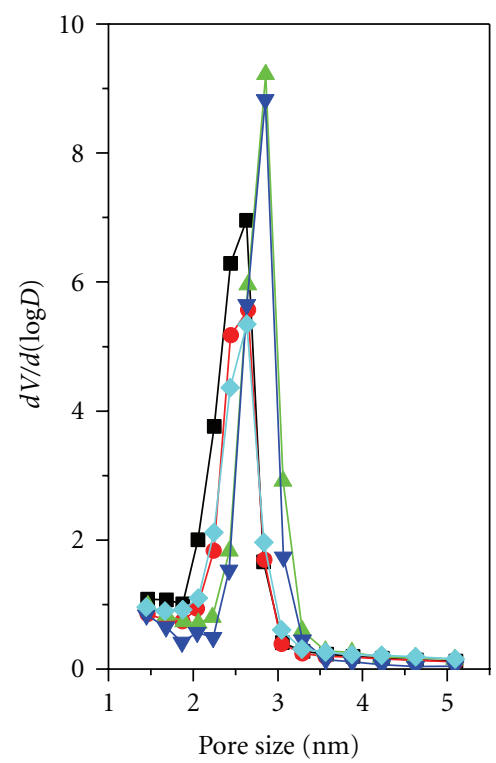

$$
\begin{aligned}
& \mathrm{Na} / \mathrm{Si}=0.5(\mathrm{OH} / \mathrm{Si}) \\
& \rightarrow \mathrm{pH}=10.8(0.42) \\
& \rightarrow \mathrm{pH}=10.7(0.34) \\
& \neg \mathrm{pH}=10.5(0.26) \\
& \neg \mathrm{pH}=10.4(0.24) \\
& \rightarrow \mathrm{pH}=10.2(0.18)
\end{aligned}
$$

(a)

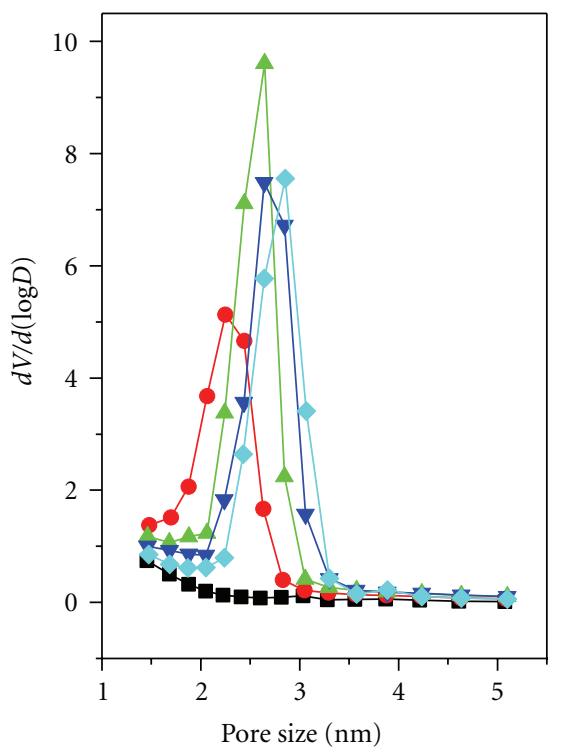

$$
\begin{aligned}
& \mathrm{Na} / \mathrm{Si}=1(\mathrm{OH} / \mathrm{Si}) \\
& \rightarrow \mathrm{pH}=11.1(0.68) \\
& \rightarrow \mathrm{pH}=10.7(0.52) \\
& \rightarrow \mathrm{pH}=10.5(0.44) \\
& \rightarrow \mathrm{pH}=10.4(0.36) \\
& \rightarrow \mathrm{pH}=10.2(0.28)
\end{aligned}
$$

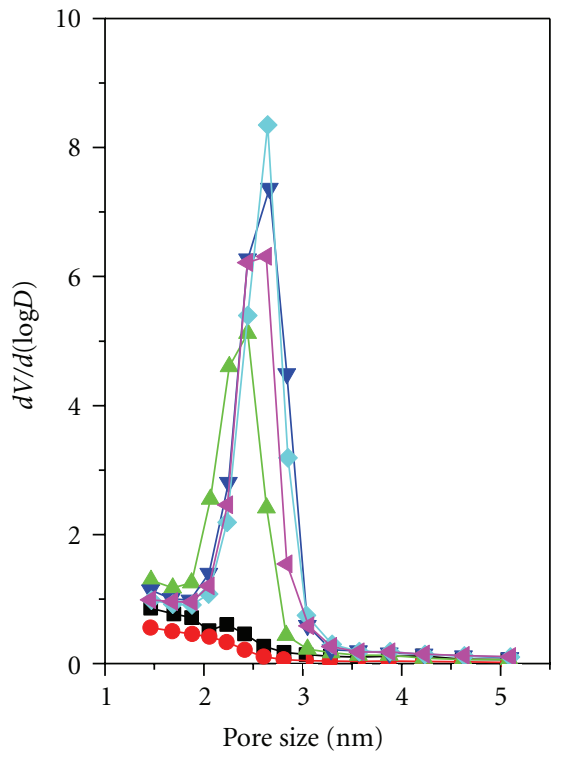

$$
\begin{aligned}
& \mathrm{Na} / \mathrm{Si}=2(\mathrm{OH} / \mathrm{Si}) \\
& \multimap \mathrm{pH}=11.1(0.8) \\
& \multimap \mathrm{pH}=11(0.72) \\
& \multimap \mathrm{pH}=10.7(0.64) \\
& \neg \mathrm{pH}=10.6(0.56) \\
& \multimap \mathrm{pH}=10.5(0.52) \\
& \longleftarrow \mathrm{pH}=10.3(0.4)
\end{aligned}
$$

(b)

(c)

FIgURE 7: Pore size distributions for the mesophase products synthesized under various $\mathrm{NaOH} / \mathrm{SiO}_{2}$ ratios prior to the pH adjustments: $\mathrm{NaOH} / \mathrm{SiO}_{2}=0.5(\mathrm{a}), \mathrm{NaOH} / \mathrm{SiO}_{2}=1.0(\mathrm{~b})$, and $\mathrm{NaOH} / \mathrm{SiO}_{2}=2.0$ (c). 


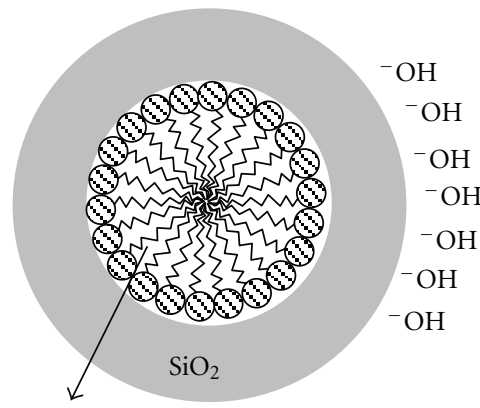

Micelle
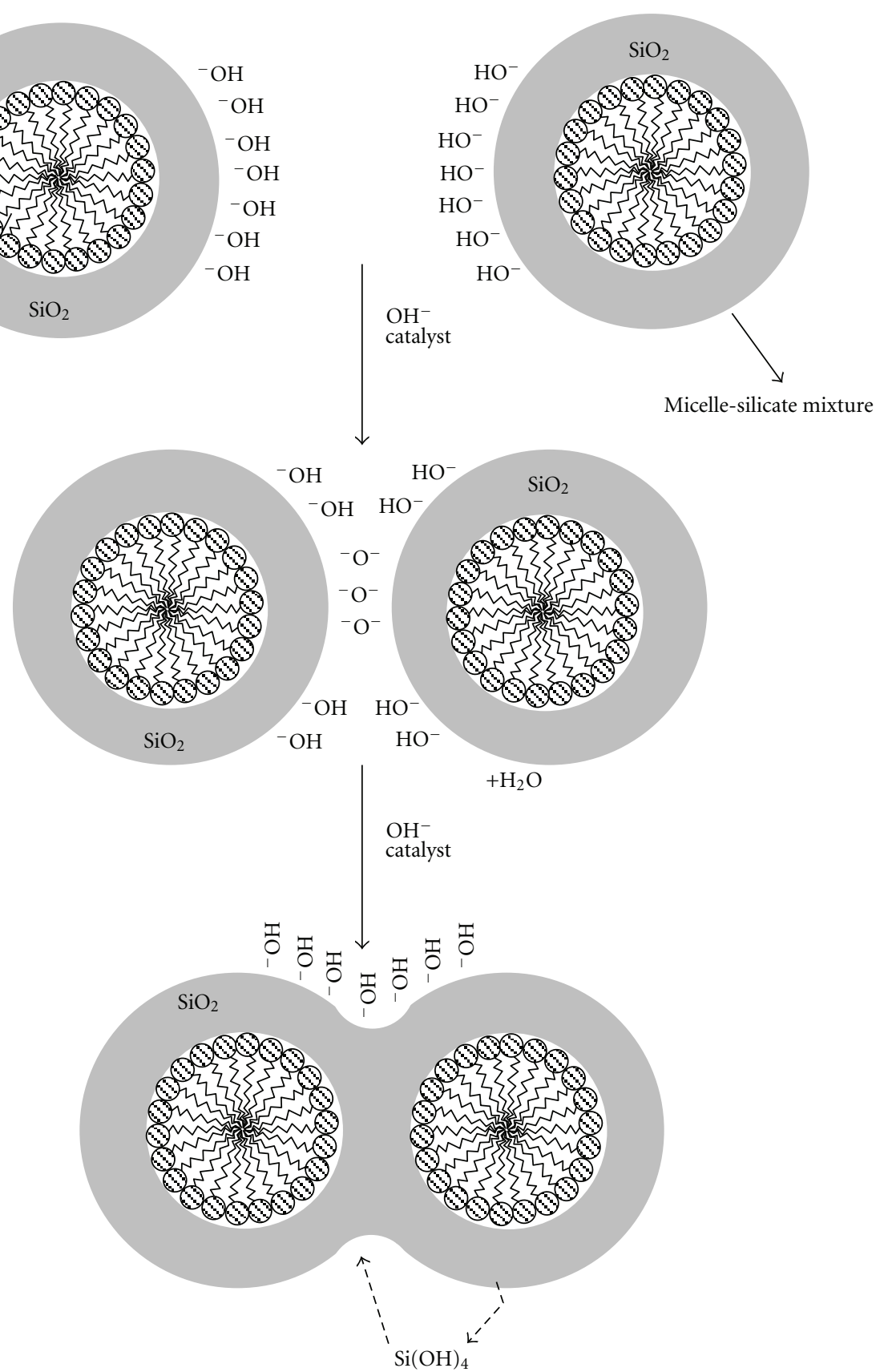

FIGURE 8: A schematic illustration for the silicate condensation phenomenon with base catalysis

on the mesopore synthesis. The synthesis conditions and specific surface areas of samples produced at $\mathrm{NaOH} / \mathrm{SiO}_{2}$ ratios of $0.5,1$, and 2 are presented in Table 2. Although the concentration of the remaining $\mathrm{OH}^{-}$was higher for the sample with $\mathrm{NaOH} / \mathrm{SiO}_{2}$ ratio of 2 than for the sample with $\mathrm{NaOH} / \mathrm{SiO}_{2}$ ratio of 0.5 , the $\mathrm{pH}$ of the solutions was same.

Although the sample for the $\mathrm{NaOH} / \mathrm{SiO}_{2}$ ratio of 2 is not expected to yield a mesophase as it will presumably condense less than the $\mathrm{NaOH} / \mathrm{SiO}_{2}$ ratio of 0.5 , the mesophase was obtained in both cases. We attribute this result to the increased amount of $\mathrm{NaCl}$ that likely led to an increased condensation of the silicate despite the excess
$\mathrm{NaOH}$. The increase in ionic strength as $\mathrm{NaCl}$ was introduced could reduce the surface charge and promote spontaneous aggregation among the micelle-silicate mixtures due to little or no repulsive forces between them. When the micellesilicate mixtures collide and aggregate with little or no charge repulsion, $\mathrm{OH}^{-}$ions in the solution play an important role in catalyzing the formation of interparticle siloxane bonds. A schematic representation of this phenomenon is given in Figure 8 [27]. Ryoo and Jun [14] previously suggested an alternative explanation for the improved mesophase synthesis. They reported that the increase in $\mathrm{NaCl}$ led to better synthesis due to the improved silicate condensation. 
TABle 2: Experimental conditions for the materials synthesized under various $\mathrm{pH}$ values and $\mathrm{NaOH} / \mathrm{SiO} \mathrm{O}_{2} \mathrm{ratios}$ and their pore characteristics.

\begin{tabular}{|c|c|c|c|c|c|}
\hline $\mathrm{pH}$ & Initial $\mathrm{NaOH} / \mathrm{SiO}_{2}$ & Contained $\mathrm{NaCl} / \mathrm{SiO}_{2}$ & Remained $\mathrm{NaOH} / \mathrm{SiO}_{2}$ & Pore volume $\left(\mathrm{cm}^{3} \mathrm{~g}^{-1}\right)$ & BET surface area $\left(\mathrm{m}^{2} \mathrm{~g}^{-1}\right)$ \\
\hline 10.8 & 0.5 & 0.08 & 0.42 & 0.66 & 863 \\
\hline 10.7 & 0.5 & 0.16 & 0.34 & 0.51 & 673 \\
\hline 10.5 & 0.5 & 0.24 & 0.26 & 0.76 & 915 \\
\hline 10.4 & 0.5 & 0.26 & 0.24 & 0.73 & 840 \\
\hline 10.2 & 0.5 & 0.32 & 0.18 & 0.56 & 718 \\
\hline 11.1 & 1 & 0.32 & 0.68 & 0.22 & 437 \\
\hline 10.7 & 1 & 0.48 & 0.52 & 0.58 & 949 \\
\hline 10.5 & 1 & 0.56 & 0.44 & 0.73 & 975 \\
\hline 10.4 & 1 & 0.64 & 0.36 & 0.67 & 845 \\
\hline 10.2 & 1 & 0.72 & 0.28 & 0.66 & 780 \\
\hline 11.1 & 2 & 1.2 & 0.8 & 0.24 & 394 \\
\hline 11 & 2 & 1.28 & 0.72 & 0.15 & 254 \\
\hline 10.7 & 2 & 1.36 & 0.64 & 0.6 & 892 \\
\hline 10.6 & 2 & 1.44 & 0.56 & 0.76 & 992 \\
\hline 10.5 & 2 & 1.48 & 0.52 & 0.65 & 837 \\
\hline 10.3 & 2 & 1.6 & 0.4 & 0.59 & 748 \\
\hline
\end{tabular}

When the $\mathrm{pH}$ was decreased from 11 to 10.2 by the addition of $\mathrm{HCl}$, the degree of silicate condensation increased. This seems to go against our assertion that the addition of salt at $\mathrm{pH}$ greater than 11 caused a reduction in the polymerization of silicate. When a micelle and silanolates interact prior to the main mesophase synthesis at $\mathrm{pH}$ greater than 11 , the presence of salt reduces the charge density of the silicate oligomers and stabilizes them as small species. Silicate growth is unlikely favored, rather small oligomers promote silicate depolymerization. Without salt, the polymerization of silicate would be promoted at $\mathrm{pH}$ less than 11 after the formation of a micelle-silicate mixture. The effect of salt on silicate polymerization thus would depend on the $\mathrm{pH}$ and the stage of synthesis.

\section{Conclusions}

Hexagonal mesoporous materials were obtained at different $\mathrm{NaOH} / \mathrm{SiO}_{2}$ ratios by the adjustment of the $\mathrm{pH}$ of the synthesis gel to examine the effects of guest ions and $\mathrm{pH}$ on the mesophase formation. The experimental results reported here suggest that the formation of the hexagonal mesophase likely depended on the charge density of the interface between organic and inorganic molecules. Thus, important parameters to synthesize mesoporous materials were all those that affected charge density: water content, guest ion concentration, and $\mathrm{pH}$. The best hexagonal mesoporous material was synthesized by lowering $\mathrm{pH}$ to the range from 10.4 to 10.6 due to the improvement of the condensation of silicate. Additionally, good mesoporous materials were obtained despite having $\mathrm{NaOH}$ content twice than that of silica. The findings from this study suggest that if anions and cations can be carefully balanced, formation of the mesophase may only depend on the degree of silicate condensation and not on the amount of guest ions in the solution.

\section{Acknowledgments}

This work was supported by the National Research Foundation of Korea Grant funded by the Korean Government (MEST) (NRF-2011-0023782).

\section{References}

[1] P. Selvam, S. K. Bhatia, and C. G. Sonwane, "Recent advances in processing and characterization of periodic mesoporous MCM-41 silicate molecular sieves," Industrial and Engineering Chemistry Research, vol. 40, no. 15, pp. 3237-3261, 2001.

[2] J. H. Park, J. K. Park, and H. Y. Shin, "The preparation of $\mathrm{Ag} / \mathrm{mesoporous}$ silica by direct silver reduction and $\mathrm{Ag} /$ functionalized mesoporous silica by in situ formation of adsorbed silver," Materials Letters, vol. 61, no. 1, pp. 156-159, 2007.

[3] F. Wang, J. Yang, and K. Wu, "Mesoporous silica-based electrochemical sensor for sensitive determination of environmental hormone bisphenol A," Analytica Chimica Acta, vol. 638, no. 1, pp. 23-28, 2009.

[4] X. B. Zhu and X. C. Duan, "Self-assembly, microstructure and photoluminescence properties of nanocomposite mesoporous silica loaded with in $_{2} \mathrm{O}_{3}$ and $\operatorname{in}_{2} \mathrm{O}_{3}-\mathrm{SnO}_{2}$," Materials Science and Technology, vol. 22, no. 12, pp. 1509-1512, 2006.

[5] B. Lindlar, A. Kogelbauer, P. J. Kooyman, and R. Prins, "Synthesis of large pore silica with a narrow pore size distribution," Microporous and Mesoporous Materials, vol. 4445, pp. 89-94, 2001.

[6] H. P. Lin and C. Y. Mou, "Studies on mesoporous selforganizing aluminosilica," Journal of Cluster Science, vol. 10, no. 2, pp. 271-293, 1999. 
[7] J. Patarin, B. Lebeau, and R. Zana, "Recent advances in the formation mechanisms of organized mesoporous materials," Current Opinion in Colloid and Interface Science, vol. 7, no. 12, pp. 107-115, 2002.

[8] M. Kruk, M. Jaroniec, J. M. Kim, and R. Ryoo, "Characterization of highly ordered MCM-41 silicas using X-ray diffraction and nitrogen adsorption," Langmuir, vol. 15, no. 16, pp. 52795284, 1999.

[9] F. Ohashi, M. Maeda, K. Inukai, M. Suzuki, and S. Tomura, "Study on intelligent humidity control materials: water vapor adsorption properties of mesostructured silica derived from amorphous fumed silica," Journal of Materials Science, vol. 34, no. 6, pp. 1341-1346, 1999.

[10] A. O. Dhokte, S. L. Khillare, M. K. Lande, and B. R. Arbad, "Synthesis, characterization of mesoporous silica materials from waste coal fly ash for the classical Mannich reaction," Journal of Industrial and Engineering Chemistry, vol. 17, no. 4, pp. 742-746, 2011.

[11] F. Y. Wei, Z. W. Liu, J. Lu, and Z. T. Liu, "Synthesis of mesoporous MCM-48 using fumed silica and mixed surfactants," Microporous and Mesoporous Materials, vol. 131, no. 1-3, pp. 224-229, 2010.

[12] H. L. Chang, C. M. Chun, I. A. Aksay, and W. H. Shih, "Conversion of fly ash into mesoporous aluminosilicate," Industrial and Engineering Chemistry Research, vol. 38, no. 3, pp. 973-977, 1999.

[13] H. P. Lin, S. Cheng, and C. Y. Mou, "Effect of delayed neutralization on the synthesis of mesoporous MCM-41 molecular sieves," Microporous Materials, vol. 10, no. 1-3, pp. 111-121, 1997.

[14] R. Ryoo and S. Jun, "Improvement of hydrothermal stability of MCM-41 using salt effects during the crystallization process," Journal of Physical Chemistry B, vol. 101, no. 3, pp. 317-320, 1997.

[15] H.-P. Lin, S. Cheng, and C.-Y. Mou, "Mesoporous molecular sieves MCM-41 with a hollow tubular morphology," Chemistry of Materials, vol. 10, no. 2, pp. 581-589, 1998.

[16] H. O. Pastore, M. Munsignatti, D. R. S. Bittencourt, and M. M. Rippel, "Study on the formation of mesoporous molecular sieves in the presence of various anions," Microporous and Mesoporous Materials, vol. 32, no. 1-2, pp. 211-228, 1999.

[17] S. Lowell and J. E. Shields, Powder Surface Area and Porosity, Chapman \& Hall, London, UK, 3rd edition, 1991.

[18] B. Echchahed, M. Morin, S. Blais, A. R. Badiei, G. Berhault, and L. Bonneviot, "Ion mediation and surface charge density in phase transition of micelle templated silica," Microporous and Mesoporous Materials, vol. 44-45, pp. 53-63, 2001.

[19] M. Grün, K. K. Unger, A. Matsumoto, and K. Tsutsumi, "Novel pathways for the preparation of mesoporous MCM-41 materials: control of porosity and morphology," Microporous and Mesoporous Materials, vol. 27, no. 2-3, pp. 207-216, 1999.

[20] R. Mokaya, "Hydrothermally-induced morphological transformation of mesoporous MCM-41 silica," Microporous and Mesoporous Materials, vol. 44-45, pp. 119-127, 2001.

[21] B. Lindlar, A. Kogelbauer, and R. Prins, "Chemical, structural, and catalytic characteristics of A1-MCM-41 prepared by $\mathrm{pH}$ controlled synthesis," Microporous and Mesoporous Materials, vol. 38, no. 2-3, pp. 167-176, 2000.

[22] M. Luechinger, L. Frunz, G. D. Pirngruber, and R. Prins, "A mechanistic explanation of the formation of high quality MCM-41 with high hydrothermal stability," Microporous and Mesoporous Materials, vol. 64, no. 1-3, pp. 203-211, 2003.

[23] F. Schüth, K. S. W. Sing, and J. Weitkamp, Handbook of Porous Solids, Wiley-VCH, Weinheim, Germany, 2002.
[24] A. Firouzi, D. Kumar, L. M. Bull et al., "Cooperative organization of inorganic-surfactant and biomimetic assemblies," Science, vol. 267, no. 5201, pp. 1138-1143, 1995.

[25] A. Galarneau, F. D. Renzo, F. Fajula, L. Mollo, B. Fubini, and M. F. Ottaviani, "Kinetics of formation of micelle-templated silica mesophases monitored by electron paramagnetic resonance," Journal of Colloid and Interface Science, vol. 201, no. 2, pp. 105-117, 1998.

[26] H. F. Huisman, "Light scattering of solutions of ionic detergents," Proceedings of the Koninklijke Nederlandse Akademie Van Wetenschappen B, vol. 67, p. 368, 1964.

[27] R. K. Iler, The Chemistry of Silica, John Wiley \& Sons, New York, NY, USA, 1979. 

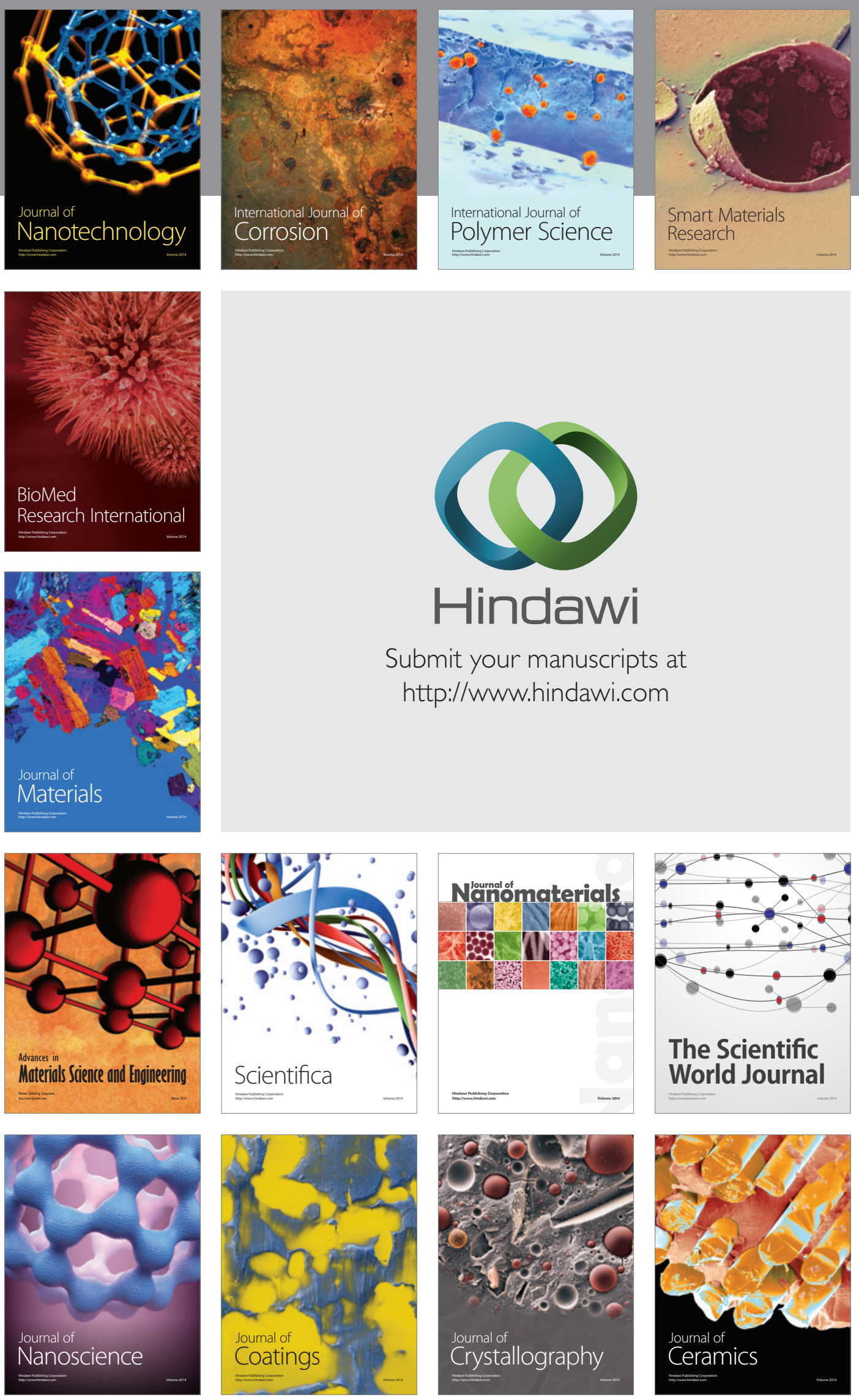

The Scientific World Journal

Submit your manuscripts at

http://www.hindawi.com

\section{World Journal}

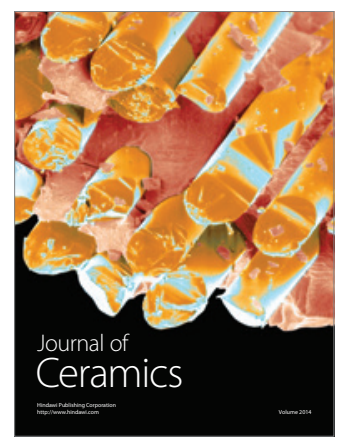

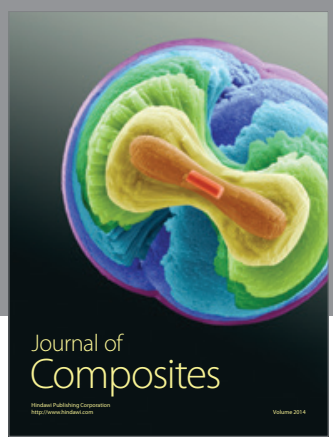
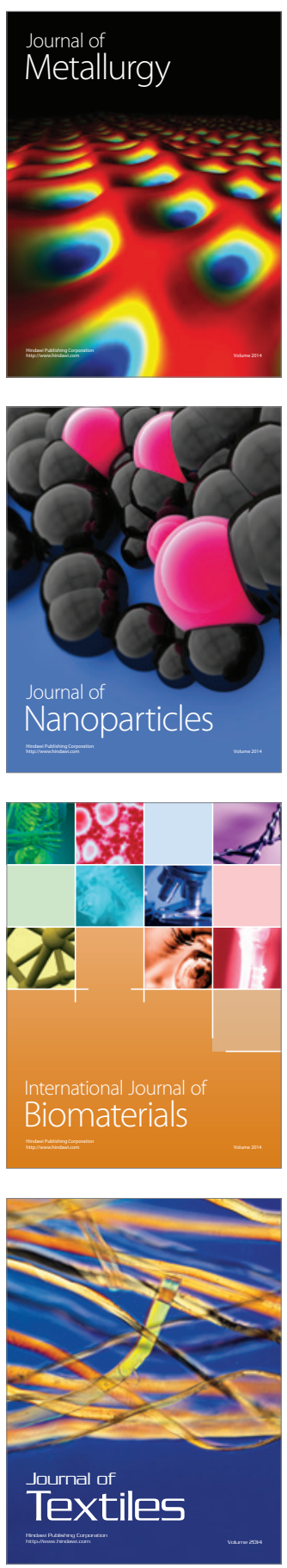